(Aus der medic. Abtheilung der Universität von Illinois in Chicago.)

\title{
Ueber Köppe's Theorie der Salzsäurebildung im Magen.
}

\author{
Von
}

John A. Wesener, M. D., Professor der Chemie.

Köppe hat vor Kurzem eine Hypothese der Salzsäurebildung im Magen aufgestellt, wonach die Bildung der freien Salzsäure im Magen durch Ionisation des im Magen enthaltenen Natriumchlorid und der im Blute vorhandenen sauren Carbonate und Phosphate entsteht, wobei die H-Ionen im Blute mit Na-Ionen im Magen ausgetauscht werden ${ }^{1}$ ). Köppe hat bisher die Richtigkeit seiner Theorie nicht bewiesen, und weitere Untersuchungen dieses Gegenstandes, die er in seiner ersten Veröffentlichung versprach, sind soweit noch nicht erschienen.

Die folgenden Versuche beweisen nun, wie es mir scheint, dass Köppe's Theorie keine thatsächliche Grundlage hat. Hungernde Magen wurden zuerst mit kaltem Wasser ausgewaschen, um den grössten Theil der Chloride und die freie Salzsäure, die oft im hungernden Magen vorbanden ist, zu entfernen ${ }^{2}$ ). Dann wurde Turck's "Gyromele" oder Drehsonde in den Magen eingeführt und durch einige Minuten rotirt. Der Mageninhalt, der vor der Einführung der Gyromele vollständig neutral gewesen, gab nun eine starke Reaction mittelst Günzburg's und Boas' Reagentien, und der Säuregehalt wurde durch Titration auf $0,1 \%(\mathrm{HCl})$ festgestellt.

1) Pflüger's Archiv Bd. 62 S. 589.

2) Das Wasser zum Waschen muss kalt sein. Warmes oder auch nur lauwarmes Wasser hat genügend stimulirende Wirkung, um beträchtliche Spuren von Salzsäure zu erzeugen. Kaltes Wasser hingegen scheint die HCl erzeugenden Zellen zu paralysiren, sogar in Fällen von Hyperacidität wird der Magen von freier Salzsäure mit kaltem Wasser rein gewaschen. Die Chloride hingegen können nicht vollständig ausgewaschen werden, wie ich schon in meinen ersten Versuchen gefunden habe (Medicus, Chicago 1895). 
484 John A. Wesener: Ueber Köppe's Theorie der Salzsäurebildung etc.

Gegen diesen Versuch kann die Einwendung gemacht werden, dass die Molecüle von $\mathrm{NaCl}$ durch die Stimulation der Gyromele aus dem Blute in den Magen ausgeschieden wurden, und dass dieses $\mathrm{NaCl}$ ionisirt und in freie Salzsäure verwandelt wurde, und zwar durch den obengenannten Austausch von Na- und H-Ionen. Das würde mit Köppe's Annahme übereinstimmen, dass die NaCl-Molecüle die Magenschleimhaut durchdringen können, während die ClIonen dies nicht thun können. Obgleich diese Voraussetzung von Köppe bei Weitem nicht bewiesen ist, wurde diese Einwendung durch folgende Versuche widerlegt:

Nach Auswaschung des Magens wurde physiologische Salzlösung $(0,7 \% \mathrm{NaCl})$ eingefübrt und etwa zehn Minuten im Magen gelassen. Wenn Köppe's Theorie richtig wäre, sollte diese Flüssigkeit jetzt mehr oder weniger freie Salzsäure enthalten. Wir konnten jedoch keine Spur mittelst Günzburg's und Bo a s' Reagentien entdecken. Wenn wir aber darnach Turck's Gyromele einfübrten, erhielten wir eine sehr starke Reaction von Salzsäure, und Titration ergab wieder eine Acidität von ungefähr $0,1 \%$ Salzsäure.

Aus diesen Versuchen müssen wir schliessen, dass Köppe's Theorie unhaltbar ist, und dass die Salzsäure, die im Magensafte vorhanden ist, ein Product der Zellactivität ist, was auch der chemische Process sein mag. Es ist noch zu erwähnen, dass die obigen Versuche $\mathrm{zu}$ wiederholten Malen, nicht nur an gesunden Personen, sondern auch an Patienten mit Hyperacidität ausgeführt wurden, und in jedem Falle war das Resultat dasselbe. Die Bildung der Salzsäure war leicht bei Gebrauch der Gyromele, d. h. durch mechanische Reizung der Magenwand, herbeizuführen, aber nicht durch Eingüsse von kalter Salzlösung. 